(6) OPEN ACCESS

\title{
Residential segregation, dividing walls and mental health: a population-based record linkage study
}

\author{
Aideen Maguire, ${ }^{1}$ Declan French, ${ }^{2}$ Dermot O'Reilly ${ }^{1}$
}

${ }^{1}$ Centre for Public Health, Queen's University, Belfast, UK ${ }^{2}$ School of Management, Queen's University, Belfast, UK

\section{Correspondence to} Dr Aideen Maguire, Centre for Public Health, Queen's University, Belfast, Royal Hospitals Site, Grosvenor Road, Belfast BT12 6BJ, UK; a.maguire@qub.ac.uk

Received 27 October 2015 Revised 20 January 2016 Accepted 24 January 2016 Published Online First 8 February 2016

\section{CrossMark}

To cite: Maguire $A$, French D, O'Reilly D. J Epidemiol Community Health 2016;70:845-854.

\begin{abstract}
Background Neighbourhood segregation has been described as a fundamental determinant of physical health, but literature on its effect on mental health is less clear. While most previous research has relied on conceptualised measures of segregation, Northern Ireland is unique as it contains physical manifestations of segregation in the form of segregation barriers (or 'peacelines') which can be used to accurately identify residential segregation.
\end{abstract}

Methods We used population-wide health record data on over 1.3 million individuals, to analyse the effect of residential segregation, measured by both the formal Dissimilarity Index and by proximity to a segregation barrier, on the likelihood of poor mental health.

Results Using multilevel logistic regression models, we found residential segregation measured by the Dissimilarity Index poses no additional risk to the likelihood of poor mental health after adjustment for area-level deprivation. However, residence in an area segregated by a 'peaceline' increases the likelihood of antidepressant medication by $19 \%(\mathrm{OR}=1.19,95 \% \mathrm{Cl}$ 1.14 to 1.23 ) and anxiolytic medication by $39 \%$ $(\mathrm{OR}=1.39,95 \% \mathrm{Cl} 1.32$ to 1.48$)$, even after adjustment for gender, age, conurbation, deprivation and crime. Conclusions Living in an area segregated by a 'peaceline' is detrimental to mental health suggesting segregated areas characterised by a heightened sense of 'other' pose a greater risk to mental health. The difference in results based on segregation measure highlights the importance of choice of measure when studying segregation.

\section{INTRODUCTION}

The physical and social characteristics of where we live can affect our health. One such characteristic, residential segregation, is acknowledged to be a fundamental determinant of physical ill health associated with risk of cancer, heart disease, obesity, low birth weight and increased infant mortality. ${ }^{1-4}$ The mechanisms underlying these associations are not well understood, but segregation is likely to play a significant role in determining access to resources such as education, employment, transport and healthcare which are all associated with health outcomes. ${ }^{5}$ Segregated areas are also associated with high rates of antisocial behaviour and crime prompted by intergroup contact, especially in the form of hate crime, sectarianism and crimes for financial gain. ${ }^{6-8}$

However, evidence for the effect of segregation on mental health has produced conflicting results. In a recent review of neighbourhood characteristics and risk of depression, only 4 out of 10 studies found an association between residential segregation and mental health. ${ }^{9}$ Furthermore, all of these studies were based in the USA or Canada, focused on racial residential segregation, with small samples of the population, and all involved self-reported measures of depression. None of the studies adjusted for crime or degree of urbanisation. Although populations can be segregated by race, religion or socioeconomic status, most US segregation studies have focused on urban racial segregation. ${ }^{3} 910$ UK studies have focused on ethnic density and not segregation, with only one study in Northern Ireland suggesting that increased residential segregation leads to increased rates of poor mental health. ${ }^{11}$ However, this study relied on area-based levels of costed utilisation of antidepressant and anxiolytic medications as the indicator of population mental health and did not adjust for individual-level characteristics risking ecological fallacy. In addition, as medication costs vary greatly by drug brand, costs may not be directly attributable to magnitude of prescribing causing noise in the data.

Northern Ireland is a country segregated along religious lines, with religion as the primary geographical divide. ${ }^{12}$ Unlike racial segregation in the USA which stemmed from segregation of new immigrants, segregation in Northern Ireland was amplified in the 1970s, during the civil conflict known colloquially as 'the Troubles'. Northern Ireland has been largely segregated into Protestant and Catholic communities since the 1900s, but after fighting erupted between opposing Nationalist (majority Roman Catholic) and Unionist (majority Protestant faith) populations in the late 1960s, segregation of these two communities intensified, resulting in what was the largest forced population movement in Western Europe since the aftermath of World War II at the time, it was supported by the local government and enshrined in social housing policies. ${ }^{13}{ }^{14}$ This residential segregation is reinforced in the wider community as almost all children (93\%) are educated in segregated schools promoting very little contact with the 'other' community. ${ }^{15}$ Physical manifestations of segregation still remain in the form of dividing walls or segregation barriers, known as 'peacelines', constructed at interfaces to keep opposing groups or communities separate (figure 1). The majority of segregation barriers are clustered in highly urban areas with around 100 documented permanent and temporary barriers in the capital city of Belfast alone. ${ }^{16}$

Psychologists have reflected on the negative psychological implications of segregation barriers such as the wall separating the West Bank from Israel in 
Figure 1 Segregation barrier in West Belfast.

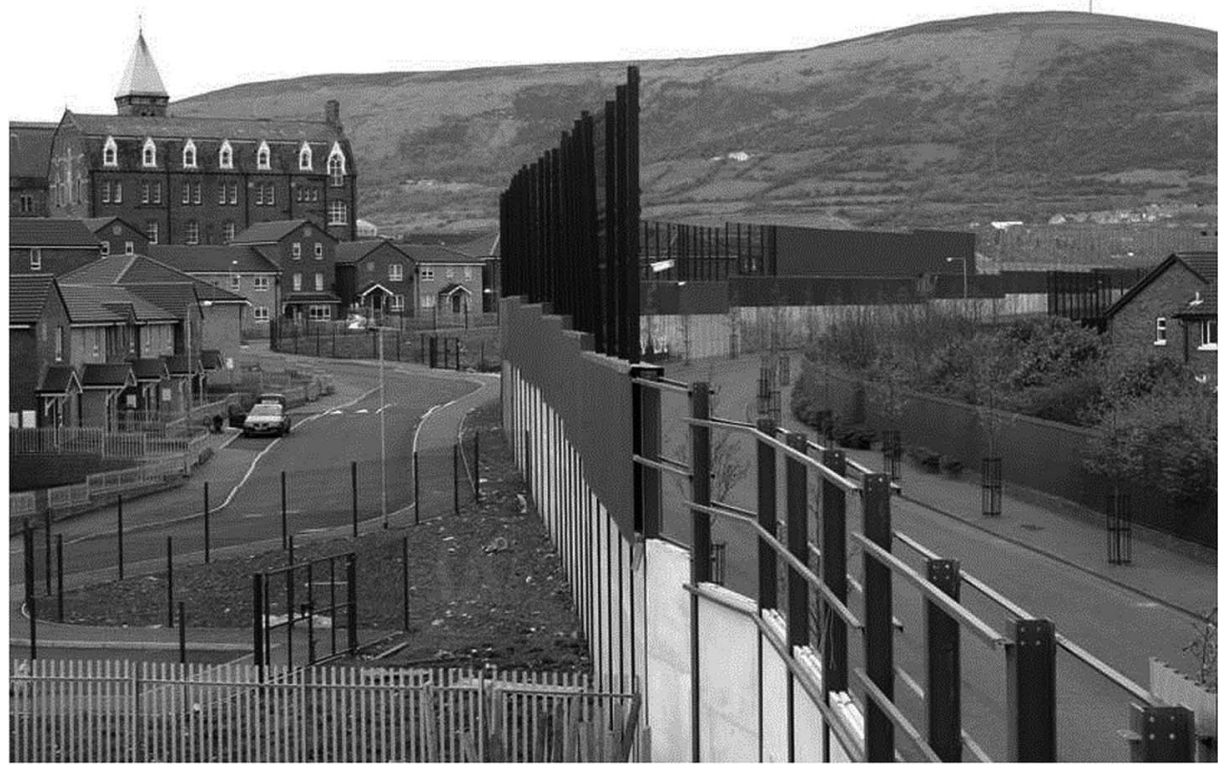

the Middle East and the 'wall effect' or reactive depression caused by the Berlin Wall; ${ }^{17}{ }^{18}$ however, no empirical evidence exists regarding the impact these sociopolitical environments have on the health and well-being of the population. Segregated areas lack social cohesion and residential stability with a steeper population decline compared with the rest of Northern Ireland, ${ }^{19}$ and have increased levels of violence, which are all deleterious to mental health. ${ }^{20}$ Segregation barriers are erected with an aim to reduce conflict and violence and create a sense of protection.

The most commonly used formal measure of residential segregation is the Dissimilarity Index, which essentially identifies the proportion of a group that would need to move in order to create a uniform distribution of the population. ${ }^{11}$ However, increasing literature on segregation has led researchers to debate the accuracy and effectiveness of this measure. ${ }^{21} 22$ The modifiable areal unit problem (MAUP) arises from a reliance on residential population data that are typically collected, aggregated and reported for spatial units that may not accurately conceptualise neighbourhoods. The checkerboard problem stems from the fact that segregation measures typically ignore the spatial proximity of neighbourhoods and focus instead only on racial composition. Northern Ireland is unique in that it contains tangible, physical manifestations of segregation in the form of segregation barriers which can be used as proxies to accurately identify segregated areas, overcoming the MAUP and allowing for a more accurate identification of interface areas with a close proximity to the 'other' community. This study will use both the formal Dissimilarity Index and proximity to a segregation barrier to test the association between segregation and poor mental health utilising population-wide linkage of individual records from administrative data sources.

The study aims to determine if segregation is associated with mental health, if the association differs depending on the use of the formal or proxy measure of segregation and if these associations can shed any light on the mechanisms underlying the association between place of residence and mental health. This is the first study of its kind to examine the effect of residential religious segregation on individual mental health in a full population cohort.

\section{METHODS}

\section{Data sources}

This was a population-based, record linkage study involving data from the National Health Applications and Infrastructure Services (NHAIS) data set linked to prescribing data on antidepressant and anxiolytic medications from the Enhanced Prescribing Database (EPD) and area-level measures of segregation, deprivation and crime. NHAIS contains information on all patients registered with a primary care physician in Northern Ireland including individual health and care number $(\mathrm{HCN}-\mathrm{a}$ unique identifier for use within the health system), demographic details, address information and details of the prescribing general practice (GP). Northern Ireland has a universal, free at the point of service healthcare system providing healthcare to almost $100 \%$ of the population, and hence almost the entire population are registered with a primary care physician. The EPD is a centralised collation of all medications dispensed to the Northern Ireland population in community pharmacies from 2008 onwards, ${ }^{23}$ and also contains individual HCN facilitating a one-to-one linkage to the NHAIS data set.

\section{Cohort description}

The study cohort consisted of all non-institutionalised individuals living in Northern Ireland aged between 18 and 74 years in 2009. The age restriction allowed for a more accurate identification of poor mental health as antidepressant and anxiolytic medications are sometimes used for indications other than mental illness in the very young and very old. ${ }^{24-26}$ Age was categorised as 18-24, 25-34, 35-44, 45-54, 55-64 and 6574 years. Address was available for all cohort members and was used to identify area-level characteristics.

\section{Area characteristics}

Census output areas (COAs) were introduced in Northern Ireland after the 2001 Census and were built from clusters of adjacent postcodes (aka zip codes). They have population sizes of around 125 households/350 people. There are 5022 COAs in Northern Ireland. Groups of five or six COAs make up the larger, most commonly used area identifier in the reporting of national geography, the super output area (SOA). In total, 
Northern Ireland is made up of 890 SOAs with an average population of 2000 people. SOAs are the optimal small area geography for reporting results as they have been designed to be as similar as possible in population size while being big enough to ensure robust estimates of area-level characteristics. Address information from NHAIS was used to assign individuals to COAs and subsequent SOAs.

\section{Segregation}

The Dissimilarity Index, D, of segregation was constructed for each SOA by calculating the proportion of individuals in each sub area (COA) that would have to move in order that the two communities, Catholic and Protestant, were spread evenly throughout the area, also taking into consideration population distribution of SOAs contiguous. More detail of the measure can be found in French (2009). ${ }^{11}$ A dichotomous variable identified areas as segregated using a benchmark of a $D \geq 0.6$. Generally, a Dissimilarity Index value above 0.60 is thought to represent extremely high segregation. ${ }^{27}$

\section{Segregation barriers}

The Department of Justice (formerly Northern Ireland Office) managed 'peacelines' were mapped using Geographical Information Systems technology in 2005 and updated in 2007 by the Belfast Interface Project (BIP) identifying 40 unique segregation barriers in Northern Ireland. ${ }^{16}$ Continuous, unbroken lines of barrier were counted as one 'peaceline', so that one barrier made up of cement wall, fencing and wire was counted as one instead of three separate structures. Each of the COAs and SOAs inhabited by a segregation barrier were identified and flagged and used to create an ordinal variable to identify proximity of residence to a segregation barrier (figure 2). Zero indicates no segregation barrier in your area (ie, those living in SOA $\mathrm{D}$ in figure 2 ), one indicates living in close proximity to a segregation barrier (those living in SOA B, COAs 7 and 8 in figure 2), and two indicates living in very close proximity to a segregation barrier (those living in SOA A, COAs 1, 2 and 5 in figure 2).

\section{Urban-rural}

There is no universally agreed definition of what constitutes an 'urban' or 'rural' area, but an approach based on population size, density and access to services has been used in the UK to produce an official classification of urbanity and this has been applied to the $5022 \mathrm{COAs}^{28}{ }^{28}$ For the purposes of this study, urban was classified as settlements of $>75000$ people and rural was classified as settlements of $<75000$ people. The urban group encompasses Northern Ireland's two largest cities which are home to almost half the population.

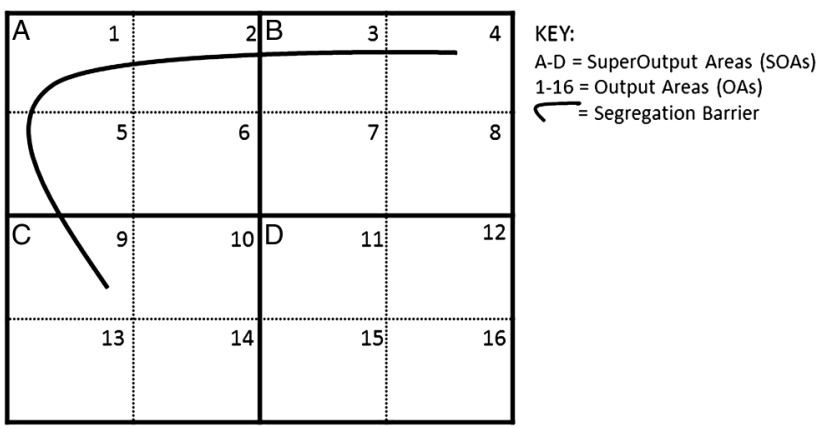

Figure 2 Tabular representation of identifying areas with a segregation barrier.

\section{Deprivation}

A measure of disadvantage was extracted from the income deprivation domain of the Northern Ireland Multiple Deprivation Measure (NIMDM), which provides information on the proportion of the population in each area living in households in receipt of income-related benefits and tax credits in 2008/2009. ${ }^{29}$ Scores were ranked and split into quintiles containing approximately equal proportions of the population identifying affluent through to deprived areas. Quintiles were used to plainly illustrate the distribution of segregation and segregation barriers throughout Northern Ireland.

\section{Crime}

Statistics on reported crime in 2008/2009 were also sourced from the NIMDM. The crime domain includes counts of recorded crime, deliberate fires and incidents of antisocial behaviour from the Police Service for Northern Ireland and the Northern Ireland Fire and Rescue Service. Scores were ranked and split into quintiles containing approximately equal proportions of the population identifying areas with high levels of reported crime through to areas with lower levels of reported crime. Though the reporting of crime may be subject to community bias, this is the only measure of crime available.

\section{Mental health outcomes}

Previous studies in this area have relied on self-reported measures of mental health. These are subject to a variety of biases, with self-rated mental health suggested to be more of a measure of well-being than of subjective mental illness, ${ }^{30}$ and with validated scales still being subject to responder and interviewer bias. In this study, receipt of anxiolytic or antidepressant medication was taken as a proxy measure of anxiety disorder or depression, identifying individuals who have sought help for a common mood disorder that is likely affecting their everyday life. Prescription information was retrieved from the EPD for all dispensed anxiolytic and antidepressant medications (British National Formulary (BNF) category 4.1.2 and 4.3) which are predominantly prescribed for depression and anxiety disorders, ${ }^{31} 32$ over the 24 -month study period, October 2008 to September 2010. This exceptional data set allows for a detailed examination of prescribing at a nationwide level. Two years' of data allowed for the identification of long-term users ruling out one-off prescriptions for transient events. Individuals were identified as anxiolytic or antidepressant medication users if they received at least three prescriptions for each drug over the study period. Sensitivity analyses were carried out using (1) a cut-off of at least six prescriptions and (2) categorising ever versus never use, yielding similar results (available on request).

\section{Data linkage}

The prescribing data were linked to the NHAIS using the unique HCN. Linkages were undertaken by the data custodians at the Business Services Organisation and the resultant research data set containing only fully anonymised data was made available to the research team. The study was approved by the Office for Research Ethics Committees Northern Ireland (ORECNI no: $10 / \mathrm{NIR} 02 / 21$ ).

\section{Analytic approach}

Analysis was divided into three stages. The first, descriptive analysis of the cohort to determine the demographic profile of the residents and the prevalence of medication use in individuals who were resident in segregated areas, either defined by the 
Dissimilarity Index or by proximity to segregation barriers, compared with that of the rest of the population. Crosstabs of dissimilarity and segregation barriers were completed to determine the potential for mismeasurement. The second stage of analysis involved the construction of two-level multilevel logistic regression models to quantify the association between segregation measured by the Dissimilarity Index and prescription drug uptake, adjusting for intrapractice variation. As the data deal with prescription information, individuals will be naturally clustered within the 356 GPs that service these areas and trends may differ between practices. Some evidence exists to suggest particular practice characteristics can affect the likelihood of prescribing. ${ }^{33}$ Models were built to adjust for age, gender, urbanicity, deprivation and levels of crime and disorder. Interactions between independent variables were tested for moderation effects based on strong suggestions from the descriptive analysis. Third, multilevel logistic regression models were constructed to determine the effect of residential proximity to a segregation barrier and likelihood of anxiolytic or antidepressant usage, adjusting for intrapractice variation. All analyses were carried out in STATA V.13.0.

\section{RESULTS}

The study cohort consisted of 1323363 individuals aged between 18 and 74 years in 2009 nested within 356 GPs. The majority of the Northern Irish population lives in nonsegregated areas with $23.0 \%$ of the population living in areas defined as segregated with a Dissimilarity Index score $\geq 0.6$, and $4.5 \%$ of the population living in areas with a segregation barrier or 'peaceline' (table 1). For the purposes of presentation in this table, proximity to a segregation barrier is dichotomised. Of those areas identified as having a segregation barrier, 93.6\% also scored $>0.6$ on the Dissimilarity Index, indicating the $D$ is accurately capturing segregated areas.

There was no significant difference in the age and gender distribution of those living in segregated or non-segregated areas. Segregated areas tended to be more urban, more deprived and have higher levels of crime compared with those non-segregated

Table 1 Percentage of the Northern Irish population aged 18-74 years (1 323 363) by demographic and area-level characteristics per segregation category

\begin{tabular}{|c|c|c|c|c|c|}
\hline & \multirow[b]{2}{*}{$\begin{array}{l}\text { Total population } \\
\mathrm{N}=1323363\end{array}$} & \multicolumn{2}{|c|}{$\begin{array}{l}\text { Segregated areas (as defined by D } \\
>0.6 \text { ) }\end{array}$} & \multicolumn{2}{|c|}{$\begin{array}{l}\text { Segregated areas (as defined by } \\
\text { barriers) }\end{array}$} \\
\hline & & $\begin{array}{l}\text { Segregated } \\
n=316485\end{array}$ & $\begin{array}{l}\text { Non-segregated } \\
\mathrm{n}=1058393\end{array}$ & $\begin{array}{l}\text { Barrier } \\
\mathrm{n}=61942\end{array}$ & $\begin{array}{l}\text { No barrier } \\
n=1312936\end{array}$ \\
\hline \multicolumn{6}{|l|}{ Gender } \\
\hline Male & 50.2 & 50.7 & 50.1 & 51.3 & 50.2 \\
\hline Female & 49.8 & 49.3 & 49.9 & 48.8 & 49.8 \\
\hline \multicolumn{6}{|l|}{ Age (years) } \\
\hline $18-24$ & 14.8 & 15.6 & 14.5 & 17.1 & 14.6 \\
\hline $25-34$ & 20.8 & 22.3 & 20.3 & 23.2 & 20.6 \\
\hline $35-44$ & 21.0 & 20.9 & 21.1 & 19.6 & 21.1 \\
\hline $45-54$ & 18.9 & 18.3 & 19.0 & 18.1 & 18.9 \\
\hline $55-64$ & 14.4 & 13.3 & 14.7 & 12.4 & 14.5 \\
\hline $65-74$ & 10.3 & 9.6 & 10.5 & 9.6 & 10.3 \\
\hline \multicolumn{6}{|l|}{ Conurbation } \\
\hline Urban & 38.9 & 52.1 & 34.9 & 91.5 & 36.4 \\
\hline Rural & 61.1 & 47.9 & 65.1 & 8.5 & 63.6 \\
\hline \multicolumn{6}{|l|}{ Deprivation } \\
\hline 1 (least) & 20.9 & 7.7 & 24.8 & 0.0 & 21.8 \\
\hline 2 & 22.0 & 16.4 & 23.7 & 0.0 & 23.0 \\
\hline 3 & 17.7 & 14.9 & 18.6 & 0.0 & 18.6 \\
\hline 4 & 20.1 & 21.8 & 19.6 & 12.9 & 20.5 \\
\hline 5 (most) & 19.3 & 39.2 & 13.4 & 87.1 & 16.1 \\
\hline \multicolumn{6}{|l|}{ Crime } \\
\hline 1 (least) & 19.9 & 16.6 & 20.9 & 0.0 & 20.8 \\
\hline 2 & 20.1 & 13.6 & 22.1 & 0.0 & 21.1 \\
\hline 3 & 20.0 & 12.9 & 22.1 & 8.3 & 20.5 \\
\hline 4 & 19.8 & 25.3 & 18.2 & 22.1 & 19.7 \\
\hline 5 (most) & 20.2 & 31.6 & 16.7 & 69.6 & 17.8 \\
\hline \multicolumn{6}{|l|}{ Segregation index } \\
\hline Dissimilarity Index $>0.6$ & 23.0 & - & - & 93.6 & 19.7 \\
\hline Dissimilarity Index $<0.6$ & 77.0 & - & - & 6.4 & 80.3 \\
\hline \multicolumn{6}{|l|}{ Segregation barrier } \\
\hline No barrier & 95.5 & 19.7 & 80.3 & - & - \\
\hline Close or very close to barrier & 4.5 & 93.6 & 6.4 & - & - \\
\hline \multicolumn{6}{|l|}{ Medication } \\
\hline Antidepressants & 13.9 & 15.6 & 13.5 & 20.5 & 13.6 \\
\hline Anxiolytics & 4.3 & 5.2 & 4.0 & 8.6 & 4.1 \\
\hline Either drug & 15.5 & 17.3 & 14.9 & 23.3 & 15.1 \\
\hline
\end{tabular}


areas. Segregation barriers were unique to deprived areas with all barriers in deprivation quintiles 4 and 5, whereas segregation defined by the Dissimilarity Index was evident in all areas, but with more than half $(61 \%)$ of areas scoring $D \geq 0.6$ falling into deprivation quintiles 4 and 5 .

Individuals living in segregated areas, either defined by the Dissimilarity Index or proximity to segregation barriers, had poorer mental health compared with those who did not live in segregated areas. In segregated areas defined by the Dissimilarity Index, $15.6 \%$ of the population received $\geq 3$ prescriptions for antidepressant medication and $5.2 \%$ received $\geq 3$ prescriptions for anxiolytic medication compared with $13.5 \%$ and $4.0 \%$, respectively, in non-segregated areas. Over one in five $(20.5 \%)$ of those living in areas with segregation barriers received $\geq 3$ prescriptions for antidepressant medication compared with $13.6 \%$ of those in areas with no barriers, and $8.6 \%$ received $\geq 3$ anxiolytic prescriptions compared with $4.1 \%$ in areas with no barriers. The percentage uptake of medication in non-segregated areas defined either way was equivalent.

\section{Segregation as measured by D and mental health}

Separate multilevel logistic models were constructed to determine the likelihood of antidepressant medication, anxiolytic medication or either medication after adjusting for individual factors, urbanicity, deprivation and level of crime. Although the trends were similar, they varied in magnitude for antidepressant and anxiolytic medication, so the results are presented for each medication separately. Table 2 illustrates the likelihood of antidepressant medication given residence in a segregated area as defined by the Dissimilarity Index. In the unadjusted model, individuals living in segregated areas are $7 \%(\mathrm{OR}=1.07,95 \%$ CI 1.06 to 1.09 ) more likely to receive medication for depression compared with those in non-segregated areas. Adjusting for age, sex and level of urbanity does not alter the association. However, after adjusting for area-level deprivation (model 4) the association disappears ( $\mathrm{OR}=1.00,95 \%$ CI 0.98 to 1.01). The same pattern is observed in analysing the likelihood of anxiolytic medication (table 3 ). In the model adjusted for age, sex and conurbation (model 3), individuals living in segregated areas are $18 \%(\mathrm{OR}=1.18,95 \% \mathrm{CI} 1.15$ to 1.20$)$ more likely to receive medication for anxiety compared with those in nonsegregated areas, but after adjusting for deprivation the association fails. Sensitivity analysis building models using the Dissimilarity Index scores in place of the dichotomised variable, allowing Dissimilarity to vary continuously, yielded similar results. In the unadjusted model, likelihood of antidepressant

Table 2 Multilevel logistic regression calculating likelihood of $\geq 3$ antidepressant medication prescriptions given area-level dissimilarity, adjusting for GP variation

\begin{tabular}{|c|c|c|c|c|c|}
\hline & Model 1 & Model 2 & Model 3 & Model 4 & Model 5 \\
\hline \multicolumn{6}{|l|}{ Segregation } \\
\hline$D<0.6$ & 1.00 & 1.00 & 1.00 & 1.00 & 1.00 \\
\hline$D>0.6$ & 1.07 (1.06 to 1.09$)$ & 1.10 (1.08 to 1.11$)$ & 1.09 (1.07 to 1.11$)$ & 1.00 (0.98 to 1.01$)$ & $1.00(0.98$ to 1.01$)$ \\
\hline \multicolumn{6}{|l|}{ Gender } \\
\hline Male & & 1.00 & 1.00 & 1.00 & 1.00 \\
\hline Female & & 2.28 (2.25 to 2.30$)$ & 2.28 (2.25 to 2.30 ) & 2.29 (2.27 to 2.32 ) & 2.29 (2.27 to 2.32$)$ \\
\hline \multicolumn{6}{|l|}{ Age (years) } \\
\hline $18-24$ & & 1.00 & 1.00 & 1.00 & 1.00 \\
\hline $25-34$ & & 1.92 (1.87 to 1.97$)$ & 1.92 (1.87 to 1.97$)$ & 1.91 (1.87 to 1.96$)$ & 1.91 (1.87 to 1.96$)$ \\
\hline $35-44$ & & 3.39 (3.32 to 3.47$)$ & 3.40 (3.32 to 3.48 ) & 3.48 (3.40 to 3.58 ) & 3.48 (3.40 to 3.56$)$ \\
\hline $45-54$ & & 4.36 (4.26 to 4.46$)$ & 4.36 (4.26 to 4.46$)$ & 4.49 (4.39 to 4.60$)$ & 4.49 (4.39 to 4.60$)$ \\
\hline $55-64$ & & 4.69 (4.58 to 4.80$)$ & 4.70 (4.59 to 4.81 ) & 4.83 (4.72 to 4.94 ) & 4.83 (4.72 to 4.95$)$ \\
\hline 65-74 & & 3.76 (3.67 to 3.85 ) & 3.76 (3.67 to 3.86 ) & 3.83 (3.74 to 3.93 ) & 3.83 (3.74 to 3.93$)$ \\
\hline \multicolumn{6}{|l|}{ Conurbation } \\
\hline Rural & & & 1.00 & 1.00 & 1.00 \\
\hline Urban & & & 1.24 (1.20 to 1.27$)$ & 1.08 (1.05 to 1.11$)$ & $1.07(1.04$ to 1.10$)$ \\
\hline \multicolumn{6}{|l|}{ Deprivation } \\
\hline 1—most affluent & & & & 1.00 & 1.00 \\
\hline 2 & & & & 1.20 (1.18 to 1.22 ) & 1.19 (1.17 to 1.21$)$ \\
\hline 3 & & & & 1.40 (1.37 to 1.42 ) & $1.38(1.35$ to 1.40$)$ \\
\hline 4 & & & & 1.66 (1.63 to 1.69$)$ & 1.62 (1.59 to 1.66$)$ \\
\hline 5-most deprived & & & & 2.06 (2.02 to 2.10$)$ & 2.02 (1.97 to 2.07$)$ \\
\hline \multicolumn{6}{|l|}{ Crime } \\
\hline 1-low crime & & & & & 1.00 \\
\hline 2 & & & & & 1.04 (1.02 to 1.06$)$ \\
\hline 3 & & & & & 1.05 (1.03 to 1.07$)$ \\
\hline 4 & & & & & $1.06(1.04$ to 1.08$)$ \\
\hline 5-high crime & & & & & 1.05 (1.03 to 1.08$)$ \\
\hline \multicolumn{6}{|c|}{$\begin{array}{l}\text { Figures represent ORs and } 95 \% \text { Cls. } \\
\text { Model 1: unadjusted. } \\
\text { Model 2: adjusted for gender and age. } \\
\text { Model 3: plus adjustment for urban/rural. } \\
\text { Model 4: plus adjustment for area level deprivation. } \\
\text { Model 5: plus adjustment for reported crime. } \\
\text { GP, general practice. }\end{array}$} \\
\hline
\end{tabular}


Table 3 Multilevel logistic regression calculating likelihood of $\geq 3$ anxiolytic medication prescriptions given area-level dissimilarity, adjusting for GP variation

\begin{tabular}{|c|c|c|c|c|c|}
\hline & Model 1 & Model 2 & Model 3 & Model 4 & Model 5 \\
\hline \multicolumn{6}{|l|}{ Segregation } \\
\hline$D<0.6$ & 1.00 & 1.00 & 1.00 & 1.00 & 1.00 \\
\hline$D>0.6$ & $1.16(1.13$ to 1.19$)$ & 1.19 (1.16 to 1.22$)$ & $1.18(1.15$ to 1.20$)$ & $1.02(1.00$ to 1.05$)$ & $1.03(1.00$ to 1.05$)$ \\
\hline \multicolumn{6}{|l|}{ Gender } \\
\hline Male & & 1.00 & 1.00 & 1.00 & 1.00 \\
\hline Female & & 1.91 (1.87 to 1.94$)$ & $1.90(1.87$ to 1.94$)$ & 1.91 (1.88 to 1.95$)$ & $1.91(1.88$ to 1.95$)$ \\
\hline \multicolumn{6}{|l|}{ Age (years) } \\
\hline $18-24$ & & 1.00 & 1.00 & 1.00 & 1.00 \\
\hline $25-34$ & & $2.29(2.18$ to 2.41$)$ & 2.29 (2.18 to 2.41$)$ & 2.28 (2.17 to 2.39$)$ & 2.28 (2.16 to 2.39$)$ \\
\hline $35-44$ & & 4.11 (3.92 to 4.31$)$ & 4.12 (3.93 to 4.32 ) & 4.26 (4.06 to 4.46$)$ & 4.26 (4.06 to 4.47$)$ \\
\hline $45-54$ & & $5.50(5.25$ to 5.76$)$ & 5.51 (5.26 to 5.78$)$ & 5.74 (5.48 to 6.02$)$ & 5.75 (5.49 to 6.02$)$ \\
\hline $55-64$ & & 6.70 (6.39 to 7.02$)$ & $6.72(6.41$ to 7.04$)$ & 7.00 (6.68 to 7.34$)$ & $7.00(6.68$ to 7.34$)$ \\
\hline $65-74$ & & 7.72 (7.36 to 8.10$)$ & 7.73 (7.37 to 8.11$)$ & 7.96 (7.59 to 8.35$)$ & 7.96 (7.58 to 8.35$)$ \\
\hline \multicolumn{6}{|l|}{ Conurbation } \\
\hline Rural & & & 1.00 & 1.00 & 1.00 \\
\hline Urban & & & $1.48(1.41$ to 1.55$)$ & $1.20(1.14$ to 1.25$)$ & $1.18(1.12$ to 1.24$)$ \\
\hline \multicolumn{6}{|l|}{ Deprivation } \\
\hline 1-most affluent & & & & 1.00 & 1.00 \\
\hline 2 & & & & 1.32 (1.28 to 1.36$)$ & $1.27(1.23$ to 1.32$)$ \\
\hline 3 & & & & $1.62(1.60$ to 1.68$)$ & $1.55(1.49$ to 1.60$)$ \\
\hline 4 & & & & 2.10 (2.03 to 2.17$)$ & 1.94 (1.87 to 2.02$)$ \\
\hline 5-most deprived & & & & 2.91 (2.82 to 3.01$)$ & $2.67(2.57$ to 2.78$)$ \\
\hline \multicolumn{6}{|l|}{ Crime } \\
\hline 1-low crime & & & & & 1.00 \\
\hline 2 & & & & & 1.12 (1.08 to 1.16$)$ \\
\hline 3 & & & & & $1.16(1.12$ to 1.20$)$ \\
\hline 4 & & & & & $1.17(1.13$ to 1.22$)$ \\
\hline 5-high crime & & & & & $1.22(1.17$ to 1.26$)$ \\
\hline \multicolumn{6}{|c|}{$\begin{array}{l}\text { Figures represent ORs and } 95 \% \mathrm{Cls.} \\
\text { Model 1: unadjusted. } \\
\text { Model 2: adjusted for gender and age. } \\
\text { Model 3: plus adjustment for urban/rural. } \\
\text { Model 4: plus adjustment for area level deprivation. } \\
\text { Model 5: plus adjustment for reported crime. } \\
\text { GP, general practice. }\end{array}$} \\
\hline
\end{tabular}

medication increased significantly with every unit increase in Dissimilarity $(\beta=0.022, \mathrm{p}<0.001)$; however, after adjusting for area-level deprivation, the coefficient loses significance $(\beta=$ $-0.0037, p=0.107)$. Full results available on request.

\section{Segregation as measured by proximity to 'peacelines' and mental health}

Table 4 illustrates the likelihood of antidepressant medication given residence in a segregated area as defined by proximity to a segregation barrier or 'peaceline'. As 'peacelines' are unique to deprived areas, the more affluent areas were excluded from this analysis to provide stricter, but fairer, comparisons with the unexposed group. A total of 521970 individuals in Northern Ireland live in the most deprived quintiles (deprivation quintiles 4 and 5), with 7.8\% (40 759) of the deprived population living close to a 'peaceline' and 3.6\% (18 719) living very close to a 'peaceline.' The reference category was defined as individuals living in deprived areas with no segregation barrier comparing individuals who lived close to a barrier (barrier at an SOA level) or very close to a barrier (barrier at a COA level). Living close to or very close to a segregation barrier is associated with a $15 \%$ increased likelihood of antidepressant medication compared with those living in deprived non-segregated areas in the unadjusted model $(\mathrm{OR}=1.15$, 95\% CI 1.11 to 1.20$)$. There is no evidence of a step-wise relationship based on proximity to segregation barrier. Adjustment for all confounders has no effect on the association. In the final model adjusted for sex, age, conurbation and crime, individuals living very close to a segregation barrier are 19\% more likely to receive antidepressant medication compared with those living in deprived non-segregated areas $(\mathrm{OR}=1.19,95 \%$ CI 1.14 to 1.23$)$.

The pattern for anxiolytic use is much more pronounced (table 5). In the unadjusted model (model 1) individuals living close to a segregation barrier are $25 \%$ more likely to receive anxiolytic medication compared with those living in deprived, non-segregated areas $(\mathrm{OR}=1.25,95 \% \mathrm{CI} 1.20$ to 1.30$)$, and those living very close are $37 \%$ more likely to receive anxiolytic medication ( $\mathrm{OR}=1.37,95 \% \mathrm{CI} 1.30$ to 1.45$)$. After full adjustment for sex, age, conurbation and reported crime the association remains. Even after adjustment for level of segregation measured using the Dissimilarity Index, the association between proximity to 'peaceline' and poor mental health remains (model 5). Individuals living in deprived segregated areas closest to a segregation barrier are $39 \%$ more likely to receive anxiolytic medication than those living in deprived non-segregated areas with no segregation barrier. There is a clear step-wise relationship between proximity to the segregation barrier and likelihood of anxiety medication. 
Table 4 Multilevel logistic regression calculating likelihood of $\geq 3$ antidepressant medication prescriptions given proximity to segregation barriers, adjusting for GP variation

\begin{tabular}{|c|c|c|c|c|c|}
\hline & Model 1 & Model 2 & Model 3 & Model 4 & Model 5 \\
\hline \multicolumn{6}{|l|}{ Presence of segregation barrier } \\
\hline Deprived no barrier (462 492) & 1.00 & 1.00 & 1.00 & 1.00 & 1.00 \\
\hline Deprived barrier SOA (40 759) & $1.15(1.12$ to 1.18$)$ & 1.18 (1.15 to 1.22$)$ & $1.18(1.14$ to 1.21$)$ & $1.17(1.13$ to 1.20$)$ & $1.17(1.13$ to 1.20$)$ \\
\hline Deprived barrier COA (18 719) & $1.15(1.11$ to 1.20$)$ & 1.21 (1.16 to 1.26$)$ & 1.20 (1.15 to 1.25$)$ & $1.19(1.14$ to 1.23$)$ & 1.19 (1.14 to 1.23$)$ \\
\hline \multicolumn{6}{|l|}{ Gender } \\
\hline Male & & 1.00 & 1.00 & 1.00 & 1.00 \\
\hline Female & & $2.29(2.27$ to 2.31$)$ & $2.29(2.27$ to 2.31$)$ & $2.29(2.27$ to 2.31$)$ & 2.29 (2.27 to 2.31$)$ \\
\hline \multicolumn{6}{|l|}{ Age (years) } \\
\hline $18-24$ & & 1.00 & 1.00 & 1.00 & 1.00 \\
\hline $25-34$ & & 1.92 (1.87 to 1.96$)$ & 1.92 (1.87 to 1.96$)$ & 1.91 (1.86 to 1.96$)$ & 1.91 (1.86 to 1.96$)$ \\
\hline $35-44$ & & 3.46 (3.38 to 3.54$)$ & 3.46 (3.38 to 3.54$)$ & 3.47 (3.39 to 3.55$)$ & 3.47 (3.39 to 3.55 ) \\
\hline $45-54$ & & 4.45 (4.35 to 4.56$)$ & 4.46 (4.36 to 4.56$)$ & 4.47 (4.37 to 4.57$)$ & 4.47 (4.37 to 4.57 ) \\
\hline $55-64$ & & 4.79 (4.68 to 4.91$)$ & 4.80 (4.69 to 4.91$)$ & 4.80 (4.69 to 4.92$)$ & 4.80 (4.69 to 4.92$)$ \\
\hline $65-74$ & & 3.81 (3.72 to 3.91 ) & 3.82 (3.72 to 3.91$)$ & 3.82 (3.72 to 3.91$)$ & 3.82 (3.72 to 3.91$)$ \\
\hline \multicolumn{6}{|l|}{ Conurbation } \\
\hline Rural & & & 1.00 & 1.00 & 1.00 \\
\hline Urban & & & $1.13(1.10$ to 1.16$)$ & $1.10(1.07$ to 1.13$)$ & 1.10 (1.07 to 1.13$)$ \\
\hline \multicolumn{6}{|l|}{ Crime } \\
\hline 1-low crime & & & & 1.00 & 1.00 \\
\hline 2 & & & & 1.06 (1.04 to 1.08$)$ & 1.06 (1.04 to 1.08$)$ \\
\hline 3 & & & & 1.10 (1.08 to 1.12$)$ & 1.10 (1.08 to 1.12$)$ \\
\hline 4 & & & & 1.15 (1.13 to 1.21$)$ & 1.15 (1.13 to 1.21$)$ \\
\hline 5-high crime & & & & $1.19(1.16$ to 1.21$)$ & $1.19(1.16$ to 1.21$)$ \\
\hline \multicolumn{6}{|l|}{ Dissimilarity Index } \\
\hline$<0.6$ & & & & & 1.00 \\
\hline$>0.6$ & & & & & 1.00 (0.98 to 1.01$)$ \\
\hline $\begin{array}{l}\text { Figures represent ORs and } 95 \% \mathrm{Cl} \\
\text { Model 1: unadjusted. } \\
\text { Model 2: adjusted for gender and } \\
\text { Model 3: plus adjustment for urba } \\
\text { Model 4: plus adjustment for repor } \\
\text { Model 5: plus adjustment for Dissi } \\
\text { COA, census output area; GP, gene }\end{array}$ & e. & & & & \\
\hline
\end{tabular}

\section{DISCUSSION}

This study aimed to determine the risk of poor mental health based on segregation measured both by the Dissimilarity Index and by proximity to segregation barriers in an attempt to understand the mechanisms underlying any association between segregation and mental health. When using the formal Dissimilarity Index as a measure of population segregation, the results suggest that segregation poses no additional risk to the likelihood of poor mental health after adjusting for area-level deprivation. However, when using proximity to a segregation barrier, that is, 'peaceline', as a proxy indicator of segregation, the results suggest that living in an area segregated by a 'peaceline' increases the likelihood of antidepressant medication by $19 \%$ and of anxiolytic medication by 39\%, even after adjusting for gender, age, level of crime and conurbation. Segregation barriers are unique to deprived areas. So living in a deprived area with a segregation barrier provides an additional risk for poor mental health over and above the known excess risk of poor mental health in deprived areas. Choice of segregation indicator changed the magnitude of the measured association between segregation and mental health.

\section{Comparison to other studies}

These findings challenge a previous study in Northern Ireland which found that segregation as measured by the Dissimilarity Index had a negative effect on mental ill health, ${ }^{11}$ though, that study relied on coarse area-level measures of antidepressant and anxiolytic prescription costs and, unlike the present work, did not adjust for individual characteristics, individual-level uptake of medications or GP variation. In the current study, adjusting for deprivation attenuated the association between area-level segregation, as measured by $\mathrm{D}$, and mental health, supporting the premise that deprivation is the major determinant of mental health. ${ }^{34}$

The findings from this study raise a number of concerns surrounding the conceptualisation of segregation. Individuals living in areas with a segregation barrier are without doubt segregated, but it may be the built environment and the segregation infrastructure, not population composition per se, that is affecting mental health in these areas.

\section{Dissimilarity Index versus 'peacelines'}

Segregation as measured by the Dissimilarity Index measures the distribution of the population in an area but tells us little about how the population use this space or how likely individuals are to interact with the 'other' group. Segregation as measured by proximity to a 'peaceline' not only illustrates how a population is distributed over space, but also highlights the physical presence of a barrier in the built environment and the physical division of communities preventing interaction with the 'other' group, which some commentators have proposed is more indicative of segregation than the distribution of groups in 
Table 5 Multilevel logistic regression calculating likelihood of $\geq 3$ anxiolytic medication prescriptions given proximity to segregation barriers, adjusting for GP variation

\begin{tabular}{|c|c|c|c|c|c|}
\hline & Model 1 & Model 2 & Model 3 & Model 4 & Model 5 \\
\hline \multicolumn{6}{|l|}{ Presence of segregation barrier } \\
\hline Deprived no barrier (462 492) & 1.00 & 1.00 & 1.00 & 1.00 & 1.00 \\
\hline Deprived barrier SOA (40 759) & $1.25(1.20$ to 1.30$)$ & $1.29(1.23$ to 1.34$)$ & 1.27 (1.22 to 1.33$)$ & 1.25 (1.19 to 1.30$)$ & 1.24 (1.18 to 1.29$)$ \\
\hline Deprived barrier COA (18 719) & $1.37(1.30$ to 1.45$)$ & 1.45 (1.37 to 1.53$)$ & 1.43 (1.36 to 1.52$)$ & 1.40 (1.33 to 1.48$)$ & 1.39 (1.32 to 1.48$)$ \\
\hline \multicolumn{6}{|l|}{ Gender } \\
\hline Male & & 1.00 & 1.00 & 1.00 & 1.00 \\
\hline Female & & 1.91 (1.88 to 1.95$)$ & 1.91 (1.88 to 1.95$)$ & 1.91 (1.88 to 1.95$)$ & 1.91 (1.88 to 1.95$)$ \\
\hline \multicolumn{6}{|l|}{ Age (years) } \\
\hline $18-24$ & & 1.00 & 1.00 & 1.00 & 1.00 \\
\hline $25-34$ & & $2.28(2.17$ to 2.40$)$ & $2.29(2.17$ to 2.40$)$ & 2.28 (2.17 to 2.39$)$ & 2.28 (2.17 to 2.39$)$ \\
\hline $35-44$ & & 4.22 (4.03 to 4.43$)$ & 4.23 (4.04 to 4.44$)$ & 4.24 (4.05 to 4.45$)$ & 4.24 (4.05 to 4.45$)$ \\
\hline $45-54$ & & 5.68 (5.42 to 5.95$)$ & 5.68 (5.42 to 5.95$)$ & 5.71 (5.45 to 5.98$)$ & 5.71 (5.45 to 5.98$)$ \\
\hline $55-64$ & & 6.92 (6.60 to 7.25$)$ & 6.93 (6.61 to 7.26$)$ & 6.95 (6.63 to 7.28$)$ & 6.95 (6.63 to 7.28$)$ \\
\hline $65-74$ & & 7.90 (7.53 to 8.29$)$ & 7.90 (7.53 to 8.29$)$ & 7.91 (7.54 to 8.30$)$ & 7.91 (7.54 to 8.30$)$ \\
\hline \multicolumn{6}{|l|}{ Conurbation } \\
\hline Rural & & & 1.00 & 1.00 & 1.00 \\
\hline Urban & & & $1.28(1.22$ to 1.34$)$ & $1.22(1.17$ to 1.28$)$ & $1.22(1.17$ to 1.28$)$ \\
\hline \multicolumn{6}{|l|}{ Crime } \\
\hline 1-low crime & & & & 1.00 & 1.00 \\
\hline 2 & & & & $1.14(1.11$ to 1.18$)$ & 1.15 (1.11 to 1.19$)$ \\
\hline 3 & & & & 1.22 (1.18 to 1.26$)$ & 1.22 (1.18 to 1.27$)$ \\
\hline 4 & & & & $1.31(1.27$ to 1.36$)$ & 1.31 (1.27 to 1.36$)$ \\
\hline 5-high crime & & & & 1.43 (1.38 to 1.48$)$ & 1.43 (1.38 to 1.48$)$ \\
\hline \multicolumn{6}{|l|}{ Dissimilarity Index } \\
\hline$<0.6$ & & & & & 1.00 \\
\hline$>0.6$ & & & & & 1.02 (0.99 to 1.04$)$ \\
\hline $\begin{array}{l}\text { Figures represent ORs and } 95 \% \mathrm{Cl} \\
\text { Model 1: unadjusted. } \\
\text { Model 2: adjusted for gender and } \\
\text { Model 3: plus adjustment for urbar } \\
\text { Model 4: plus adjustment for repor } \\
\text { Model 5: plus adjustment for Dissi } \\
\text { COA, census output area; GP, gene }\end{array}$ & e. & & & & \\
\hline
\end{tabular}

communities. $^{35} 36$ Four mechanisms have been suggested as plausible mediating pathways for the observed association between segregation and poor health outcomes: (1) residential segregation begets individual socioeconomic status; (2) segregation perpetuates unhealthy environments; (4) segregation modifies social capital; and (4) segregation modifies risk behaviours or exposure to stressful stimuli. ${ }^{21}$ This study illustrates that the effect of segregation as measured by the Dissimilarity Index on mental health is mediated by neighbourhood socioeconomic status. However, the effect of segregation as measured by proximity to 'peacelines' on mental health is attenuated but not fully explained by neighbourhood socioeconomic status, neighbourhood crime or segregation as measured by the Dissimilarity Index. Based on the four aforementioned mechanisms this would suggest proximity to a 'peaceline' may modify risk behaviours or exposure to stressful stimuli.

The likelihood of receiving medication for anxiety disorders was higher in areas defined by segregation barriers than the likelihood of receiving medication for depression, suggesting the stress or anxiety provoking nature of the environment. The protective walls and barriers between communities in Northern Ireland have become a focal point for low-level and localised violence, which may not be captured in the formal crime and disorder measure. A sense of permanent threat in these areas as ongoing sectarian violence exacerbates social, psychological and environmental difficulties may contribute to the likelihood of receiving anxiolytic medication. ${ }^{37}$ Therefore, residential segregation may affect risk of anxiety disorder more so than risk of depression. In addition, historically, these areas witnessed most of the politically motivated violence associated with the 'troubles' ${ }^{38}$ Evidence suggests that the likelihood of psychological morbidity increases the greater the extent to which the troubles affected a person's area or life. ${ }^{39}$ However, for events from the past to affect current mental health status, we would have to assume little migration from these areas and in addition, many younger residents were born after the peace process and are unlikely to have been directly affected. Furthermore, individuals identified as suffering conflict-related trauma are not exclusively located in those areas characterised by intense violence during the 'troubles'. ${ }^{40}$ It is difficult to disentangle the effect of segregation on mental health for those who live close or very close to 'peacelines' from the historical impact of the troubles, ongoing sectarian violence and the effect the barriers have on the landscape.

Recent research on racial segregation has also focused on the effect of perceived discrimination. A systematic review of selfreported racism and health found a negative association with mental health even after adjustment for confounders. ${ }^{41}$ The majority of the reviewed studies (86\%) were based in the USA but an English study of 2054 employed adults found strong associations between perceived racial/ethnic discrimination and common mental disorders. ${ }^{42}$ Perceived discrimination was not 
measured in this study and the higher prevalence of poor mental health in segregated areas defined by both the Dissimilarity Index and proximity to segregation barriers may be due in part to the degree of perceived discrimination.

It is important to note that physical manifestations of segregation, such as barriers, also affect the lived environment in terms of street connectivity and access to resources which are evidenced as being associated with poor mental health. ${ }^{20}$ 'Peaceline' areas also contain a lot of graffiti and derelict buildings which have been suggested as negative neighbourhood attributes which can have a deleterious effect on mental health. ${ }^{43}$ These factors were not adjusted for in the current study and may go some way in explaining the observed association between poor mental health and residential proximity to 'peacelines'.

\section{Potential limitations}

This data linkage project captures information on the entire Northern Ireland population aged 18-74 years and thus has all the advantages of a population-wide study. However, it does rely on arbitrary geographic identification of areas which may not accurately conceptualise neighbourhoods, though the area measures with approximately 350 people, contain finer detailed information than previous work which has relied on census tract delineations of up to 9000 people. ${ }^{4}$ In addition, our measure of proximity to a 'peaceline', like all segregation measures, is aspatial and it is plausible that someone in a neighbouring SOA actually lives closer to the barrier than someone in the SOA depending on where the barrier is located. However, this does not alter the observed associations. Given the polarised nature of the Northern Irish society in terms of the spatial distribution according to religious affiliation, there are potentially many more segregated 'interface' areas that are not characterised by a separation barrier. For example, communities have also been separated by urban design in terms of road widening and motorway construction, but these forms of barrier differ substantially from the 'peaceline' which is the focus of this paper. In addition, 'peacelines' themselves may in fact have a protective effect at these interface areas and were the barrier to be removed mental health may decline. This is a cross-sectional study and it is difficult to determine whether the barriers were built as a result of tensions in the area or if the building of the barriers has in fact contributed to tensions.

\section{CONCLUSION}

This is the first study of its kind to document individual-level anxiolytic and antidepressant medication uptake of those living in highly segregated areas in Northern Ireland. Living in a segregated area defined by proximity to a 'peaceline' is associated with a detrimental effect on mental health. Residential segregation defined by the Dissimilarity Index appears to pose no additional risk to mental health after adjustment for deprivation. This supports the theory that residential segregation is likely to play a role in determining socioeconomic status; hence, adjustment for level of deprivation attenuates the observed relationship between segregation and mental ill health. It may be that community tensions and the heightened sense of 'other' in 'peaceline' areas are more indicative of poor mental health than segregation itself. Residence in segregated areas with high tensions or at interface areas close to the 'other' community may be more detrimental to mental health than residence in segregated areas without these attributes.

This study also highlights the importance of choice of segregation index when measuring the effect of segregation on mental health and supports demands for a more rigorous appraisal of commonly used segregation measures. ${ }^{4}$ In future studies, the environmental expression of segregation (walls, barriers, neighbourhood degeneration) needs to be taken into account and adjusted for to determine the mechanism underlying the association between segregation and health. In Northern Ireland, local policy makers are campaigning for the segregation barriers to be removed permanently. ${ }^{44}$ Although the current study cannot guide policy on whether the walls should remain or come down, their removal would provide an excellent opportunity for a natural experiment examining the impact of barrier removal on mental health. In a research report into attitudes towards the 'peacelines', although $58 \%$ of the population stated they would like to see the walls come down sometime in the future, 69\% maintained that the segregation barriers are still necessary because of the potential for violence. ${ }^{45}$ Physical manifestations of segregation, community tensions and a heightened sense of 'other' more so than segregation itself may impact population mental health and future studies should systematically assess the associations between the multiple conceptualisations of segregation.

\section{What is already known on this subject}

- Neighbourhood segregation has been described as a fundamental determinant of physical health, but literature on its effect on mental health is less clear.

- The majority of literature to date focuses on US racial segregation and recently queries have been raised about the accuracy of segregation measures.

- No UK study exists which has looked at religious residential segregation and mental health, and Northern Ireland provides a unique opportunity for segregation research.

\section{What this study adds}

- Nationwide Northern Irish data on over 1.3 million individuals suggest residence in an area segregated by a dividing wall, or 'peaceline', is deleterious to mental health.

- Residential segregation as measured by the Dissimilarity Index poses no additional risk to mental health after adjustment for socioeconomic status.

- Physical manifestations of segregation, community tensions and a heightened sense of 'other' more so than segregation itself may impact population mental health and future studies should systematically assess the associations between the multiple conceptualisations of segregation.

Twitter Follow Aideen Maguire at @Aideen_CoE

Acknowledgements The authors would like to thank the staff at the Business Services Organisation for extracting the sample data for this analysis, and Paul McErlane for providing the image of the 'Peacline'.

Contributors Each of the authors contributed to the preparation and editing of the manuscript. AM designed the study, completed the analysis and literature review. DF aided in the design of the analytical strategy and provided expertise in the Dissimilarity Index. DO contributed to the study design, literature review and preparation of the text.

Funding This work was supported by the Economic and Social Research Council (ES/G007438/1). 
Disclaimer The funding body was not involved in the design or conduct of the study, collection, management, analysis or interpretation of the data, or preparation, review or approval of the manuscript.

Competing interests None declared.

Provenance and peer review Not commissioned; externally peer reviewed.

Data sharing statement Individual level health and residence data collated for this study were given ethical approval limited to use for this study only.

Open Access This is an Open Access article distributed in accordance with the terms of the Creative Commons Attribution (CC BY 4.0) license, which permits others to distribute, remix, adapt and build upon this work, for commercial use, provided the original work is properly cited. See: http://creativecommons.org/ licenses/by/4.0/

\section{REFERENCES}

1 Williams DR, Collins C. Racial residential segregation: a fundamental cause of racial disparities in health. Public Health Rep 2001;116:404-16.

2 Kershaw KN, Diez Roux AV, Burgard SA, et al. Metropolitan-level racial residential segregation and black-white disparities in hypertension. Am J Epidemiol 2011;174:537-45.

3 Grady SC. Racial disparities in low birthweight and the contribution of residential segregation: a multilevel analysis. Soc Sci Med 2006;63:3013-29.

4 Kramer MR, Cooper HL, Drews-Botsch CD, et al. Do measures matter? Comparing measures of racial residential segregation. Int I Health Geogr 2010;9:1-15.

5 Tunstall HVZ, Shaw M, Dorling D. Places and health. I Epidemiol Community Health 2004;58:6-10.

6 Wu D, Wu Z. Crime, inequality and unemployment in England and Wales. Appl Econ 2012;44:3765-75.

7 Marian D. Sectarianism and hate Crime in Northern Ireland. In: Hall N, Corb A, Giannasi $\mathrm{P}$, et al, eds. The Routledge International Handbook on Hate Crime. Routledge, 2015:117-28.

8 Bhavnani R, Donnay K, Miodownik D, et al. Group segregation and urban violence. Am J Pol Sci 2014;58:226-45.

9 Mair C, Diez Roux AV, Galea S. Are neighbourhood characteristics associated with depressive symptoms? A review of evidence. J Epidemiol Community Health 2008;62:940-6, 8 p following 946.

10 Subramanian SV, Acevedo-Garcia D, Osypuk TL. Racial residential segregation and geographic heterogeneity in black/white disparity in poor self-rated health in the US: a multilevel statistical analysis. Soc Sci Med 2005;60:1667-79. http://dx.doi. org/10.1016/j.socscimed.2004.08.040

11 French D. Residential segregation and health in Northern Ireland. Health Place 2009;15:888-94.

12 Shuttleworth I, Gould M, Barr P. Perspectives on social segregation and migration: spatial scale, mixing and place. In: Lloyd C, Shuttleworth IG, Wong DW, eds. Social-spatial segregation: concepts, processes and outcomes. Bristol: Policy Press, 2014:197-221

13 Tonge J. Conflict and change. 2nd edn. Northern Ireland: Routledge, 2013.

14 O'Duffy B, O'Leary B. Violence in Northern Ireland, 1969-June 1989. In: McGarry J, O'Leary B, eds. The Future of Northern Ireland. Oxford: Clarendon Press, 1990.

15 Department of Education Northern Ireland. Integrated Schools. 2015. http://www. deni.gov.uk/index/85-schools/10-types_of_school-nischools_pg/16-schoolsintegratedschools_pg.htm (accessed 21 Jan 2015).

16 Jarman N. Interface Mapping Project. Belfast: 2005

17 Leuenberger $C$. Constructions of the Berlin Wall: how material culture is used in psychological theory. Soc Probl 2006;53:18-37.

18 Müller-Hegemann D. Die Berliner Mauerkrankheit. Bielefeld, Deutschland: Nicolaische Verlagsbuchhandlung, 1973

19 Plöger J. Belfast City Report. Belfast: 2007.
20 Diez Roux AV, Mair C. Neighborhoods and health. Ann N Y Acad Sci 2010;1186:125-45.

21 Kramer MR, Hogue CR. Is segregation bad for your health? Epidemiol Rev 2009:31:178-94.

22 Reardon SF, Sullivan DO. Measures of spatial segregation. Sociol Methodol 2004;34:121-62.

23 Maguire A, Hughes C, Cardwell C, et al. Psychotropic medications and the transition into care: a national data linkage study. I Am Geriatr Soc 2013;61:215-21.

24 Burke JR, Mizusawa Y, Chan A, et al. A comparison of amitriptyline, vasopressin and amitriptyline with vasopressin in nocturnal enuresis. Pediatr Nephrol 1995;9:438-40.

25 Rao A, Cohen HJ. Symptom management in the elderly cancer patient: fatigue, pain, and depression. J Nat/ Cancer Inst Monogr 2004;32:150-7.

26 Haslam C, Nurmikko T. Pharmacological treatment of neuropathic pain in older persons. Clin Interv Aging 2008;3:111-20.

27 Massey DS, Denton NA. Hypersegregation in U.S. metropolitan areas: black and Hispanic segregation along five dimensions. Demography 1989;26:373-91.

28 NISRA. Report of the Inter-Departmental Urban-Rural Definition Group. Statistical classification and delineation of settlements. 2005.

29 NISRA. Northern Ireland Multiple Deprivation Measure (NIMDM). 2010.

30 Levinson D, Kaplan G. What does self-rated mental health represent. J Public Health Res 2014;3:122-7.

31 Gardarsdottir H, Egberts AC, van Dijk L, et al. An algorithm to identify antidepressant users with a diagnosis of depression from prescription data. Pharmacoepidemiol Drug Saf 2009;18:7-15.

32 Henriksson S, Boëthius G, Håkansson J, et al. Indications for and outcome of antidepressant medication in a general population: a prescription database and medical record study, in Jamtland county, Sweden, 1995. Acta Psychiatr Scand 2003;108:427-31.

33 Tsimtsiou Z, Ashworth M, Jones R. Variations in anxiolytic and hypnotic prescribing by GPs: a cross-sectional analysis using data from the UK Quality and Outcomes Framework. Br J Gen Pract 2009;59:e191-8.

34 Fryers T, Melzer D, Jenkins R. Social inequalities and the common mental disorders: a systematic review of the evidence. Soc Psychiatry Psychiatr Epidemiol 2003;38:229-37.

35 Taylor C, Gorard S, Fitz J. A re-examination of segregation indices in terms of compositional invariance. Soc Res Update 2000;30:1-4.

36 Malmberg B, Andersson E, Östh J. Segregation and urban unrest in Sweden. Urban Geogr 2013;34:1031-46.

37 Conway M, Byrne J. Interface issues. An annotated bibliography. Belfast: 2005.

38 Shirlow P, Murtagh B. Belfast: segregation, violence and the city. London: Pluto Press, 2006.

39 O'Reilly D, Stevenson M. Mental health in Northern Ireland: have 'the Troubles' made it worse? J Epidemiol Community Health 2003;57:488-92.

40 Bunting B, Ferry F, Murphy $\mathrm{S}$, et al. Troubled consequences: a report on the mental health impact of the civil conflict in Northern Ireland. 2011.

41 Paradies Y. A systematic review of empirical research on self-reported racism and health. Int J Epidemiol 2006;35:888-901.

42 Bhui K, Stansfeld S, McKenzie K, et al. Racial/ethnic discrimination and common mental disorders among workers: findings from the EMPIRIC study of ethnic minority groups in the United Kingdom. Am J Public Health 2005;95: 496-501.

43 Leslie E, Cerin E. Are perceptions of the local environment related to neighbourhood satisfaction and mental health in adults? Prev Med (Baltim) 2008:47:273-8

44 Byrne J, Gormley-Heenan C, Robinson G. Peace Walls, Public Attitudes and Impact on Policy. 2012.

45 Byrne J, Gormley-Heenan C, Robinson G. Attitudes to Peace Walls. 2012. 